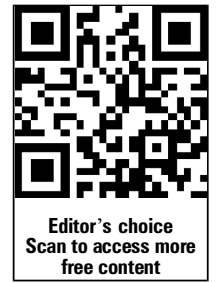

'Department of Neonatology, Helen Schneider Hospital for Women, Rabin Medical Center, Petach Tikva, Israel

${ }^{2}$ Sackler School of Medicine, Tel Aviv University, Tel Aviv, Israel

${ }^{3}$ Departments of Obstetrics and Gynecology, Helen Schneider Hospital for Women, Rabin Medical Center, Petach Tikva, Israel

${ }^{4}$ Neonatal Intensive Care Unit, Schneider Children's Medical Center of Israel, Petach Tikva, Israel

\section{Correspondence to} Professor Nehama Linder, Department of Neonatology, Rabin Medical Center, Beilinson Hospital, Petach Tikva 49100, Israel; nehama.linder@gmail.com

Received 7 August 2013 Revised 3 April 2014 Accepted 4 April 2014 Published Online First 3 May 2014

\section{SLinked}

http://dx.doi.org/10.1136/ fetalneonatal-2013-305894

To cite: Linder $N$, Lahat $Y$ Kogan A, et al. Arch Dis Child Fetal Neonatal Ed 2014;99:F353-F358.

\title{
Macrosomic newborns of non-diabetic mothers: anthropometric measurements and neonatal complications
}

\author{
N Linder, ${ }^{1,2}$ Y Lahat, ${ }^{1}$ A Kogan, ${ }^{1}$ E Fridman, ${ }^{1}$ F Kouadio, ${ }^{1}$ N Melamed, ${ }^{2,3}{ }^{3}$ Y Yogev, ${ }^{2,3}$ \\ G Klinger ${ }^{2,4}$
}

\section{ABSTRACT}

Objective To assess the association of anthropometric measurements with neonatal complications in macrosomic newborns of non-diabetic mothers.

Design Retrospective cohort study.

Patients All liveborn, singleton, full term newborns with birth weight $\geq 4000 \mathrm{~g}$ born to non-diabetic mothers at a tertiary medical centre in 1995-2005 $(n=2766$, study group) were matched to the next born, healthy, full term infant with a birth weight of 3000-4000 g (control group). Exclusion criteria were multiple birth, congenital infection, major malformations and pregnancy complications

Intervention Data collection by file review.

Outcome measures Complication rates were compared between study and control groups and between symmetric and asymmetric macrosomic newborns, defined by weight/length ratio (WLR), Body Mass Index and Ponderal Index.

Results The 2766 non-diabetic macrosomic infants identified were matched to 2766 control infants. The macrosomic group had higher rates of hypoglycaemia $(1.2 \%$ vs $0.5 \%, p=0.008)$, transient tachypnoea of the newborn $(1.5 \%$ vs $0.5 \%, p<0.001)$, hyperthermia $(0.6 \%$ vs $0.1 \%, p=0.012)$, and birth trauma ( $2 \%$ vs $0.7 \%, p<0.001$ ), with no cases of symptomatic polycythaemia, and only one case of hypoglycaemia. Hypoglycaemia was positively associated with birth weight. It was significantly higher in the asymmetric than the symmetric macrosomic newborns, defined by WLR $(1.7 \%$ vs $0.3 \%, p<0.001)$

Conclusions Macrosomic infants of non-diabetic mothers are at increased risk of neonatal complications. However, routine measurements of haematocrit and calcium may not be necessary. Symmetric macrosomic infants (by WLR) have a similar rate of hypoglycaemia as normal-weight infants. Thus, repeat glucose measurements in symmetric macrosomic infants are not justified.

\section{INTRODUCTION}

There is no consensus regarding the definition of macrosomia, and the term may be applied to newborns with a birth weight greater than 4000 , 4500 , or $5000 \mathrm{~g}$, irrespective of gestational age. ${ }^{1}$ The American College of Obstetricians and Gynaecologists suggests a threshold of $4500 \mathrm{~g}$, as morbidity increases sharply beyond this birth weight. ${ }^{2}$

The prevalence of macrosomia has been rising in recent decades, with an accompanying increased risk of adverse outcomes for mother and newborn. Risks to the newborn include shoulder dystocia, ${ }^{3}$

\section{What is already known on this topic}

The prevalence of macrosomia has been rising, with an accompanying increased risk of adverse outcomes.

- Macrosomic newborns are at an increased risk of hypoglycaemia, which is positively associated with birth weight.

\section{What this study adds}

- Symptomatic hypocalcaemia and polycythaemia are rare in macrosomic infants of non-diabetic mothers; routine measurements of haematocrit and calcium may not be required.

- Symmetric macrosomic infants (defined by weight/length ratio) have a similar rate of hypoglycaemia as normal weight infants.

- Repeated glucose measurements in symmetric macrosomic infants are not justified.

hypoxia, plexus injuries, ${ }^{4}$ hypoglycaemia, congenital anomalies, and need for intensive care. ${ }^{56}$

The aim of the present study was to quantify the rates of neonatal complications in macrosomic newborns born to non-diabetic mothers; compare these rates between symmetric and asymmetric macrosomic subgroups, defined according to anthropometric indices, and explore possible correlations of neonatal morbidities with anthropometric measurements in macrosomic subgroups.

\section{MATERIALS AND METHODS}

Patients and setting

This study was approved by the local institutional research review board. A retrospective cohort study design was used. The computerised discharge records database of Rabin Medical Center, a tertiary university-affiliated hospital, was searched for all liveborn, singleton, full term (37-41 completed gestational weeks) neonates with a birth weight of $\geq 4000 \mathrm{~g}$ who were born between January 1995 and December 2005. Exclusion criteria were pregnancy complicated by multiple births, maternal diabetes (one or more abnormal glucose levels), ${ }^{7}$ maternal hypertension and/or toxaemia, placental abruption, amnionitis, acute and/or chronic fetal 
distress, or impaired fetal growth, and presence of neonatal congenital infection, major congenital malformations, chromosomal aberrations, or congenital syndromes. For each infant in the study group, the next born appropriate-for-gestational age (AGA) ( \pm 1 week) singleton infant with a birth weight of $3000-$ $4000 \mathrm{~g}$ was selected for the control group.

\section{Data collection}

Maternal and neonatal data were extracted from the medical records of the High-Risk Pregnancy Unit, Delivery Room, and Neonatal Department, as follows: maternal demographic and obstetrical characteristics: age, parity, mode of delivery, date and hour of birth (with risk hours defined as 1600 to 0800 and weekends); neonatal characteristics: gestational age, birth weight, length, head circumference, sex, perinatal mortality, number of days in the neonatal intensive care unit (NICU), hospital length of stay, 5 min Apgar score, umbilical cord blood $\mathrm{pH}$, blood pressure, neurological disorders (hypoxic ischaemic encephalopathy, convulsions), related birth injuries, hypoglycaemia, hypocalcaemia, unexplained hyperbilirubinemia, metabolic acidosis, polycythaemia, meconium aspiration syndrome, respiratory morbidity (including transient tachypnoea of the newborn, respiratory distress syndrome, and the need for oxygen administration or mechanical ventilation), hyperthermia, cyanotic episodes, culture results, neonatal leukocytosis (white blood cell count $\geq 30000 / \mathrm{mm}^{3}$ ), leukopoenia (white blood cell count $\leq 5000 / \mathrm{mm}^{3}$ ) and thrombocytopenia (platelet count $\leq 150000 / \mathrm{mm}^{3}$ ), and loss of $>10 \%$ of birth weight.

\section{Measurements and definitions}

Weight and length were measured by standard paediatric procedures. ${ }^{8} 9$ Birth weight is routinely measured by trained nurses within $1 \mathrm{~h}$ of delivery using electronic scales accurate to $5 \mathrm{~g}$ and calibrated before each measurement. Crown-heel length is measured at the same time to the nearest millimeter with an infantometer, with the head placed against the head plate and the knees fully extended.

Weight/length ratio (WLR) (weight/length, kg/m), Body Mass Index (BMI) (weight/length $/ \mathrm{m}^{2}$ ) and Ponderal Index (PI) (weight/length ${ }^{3}, \mathrm{~g} / \mathrm{cm}^{3 * 100)}$ were calculated for all infants. Asymmetry was defined as an index value above the 90th percentile. $^{10-15}$

Macrosomia was defined as birth weight $\geq 4000 \mathrm{~g}$ irrespective of gestational age. ${ }^{16}$ AGA was defined as birth weight between the 10th and 90th percentile. ${ }^{17}$ Hypoglycaemia was defined as blood glucose $<40 \mathrm{mg} / \mathrm{dL}(2.2 \mathrm{mmol} / \mathrm{L})$ at any period during the hospital stay, irrespective of gestational age or hour of life. ${ }^{18}$ Hyperthermia was defined as temperature $>37.6^{\circ} \mathrm{C}$, persisting $>1 \mathrm{~h}$. Unexplained hyperbilirubinemia was defined as any serum bilirubin value $>10 \mathrm{mg} / \mathrm{dL}(170 \mathrm{mmol} / \mathrm{L})$ before $24 \mathrm{~h}$ of age and/or $>13 \mathrm{mg} / \mathrm{dL}$ after $24 \mathrm{~h}$ of age, in the absence of active haemolysis, blood group incompatibility, glucose 6-phosphatase deficiency, or other identifiable cause of hyperbilirubinemia, such as sepsis. ${ }^{19}$ Polycythaemia was defined as peripheral venous haematocrit $>0.65(65 \%) .{ }^{20}$ Hypoxic ischaemic encephalopathy was defined as a capillary or arterial $\mathrm{pH}<7.00$ and/or base deficit $<-16$. Hypocalcaemia was defined as calcium $<7.5 \mathrm{mg} / \mathrm{dL}$. Prolonged hospitalisation was defined as an admission for more than 5 days for neonates delivered by caesarean section, and 3 days for vaginal delivery. The composite outcome was defined as the presence of one or more of the following morbidities: 5 min Apgar score $<7$, hypoxic ischaemic encephalopathy, convulsions, birth injury, hypoglycaemia, hypocalcaemia, unexplained hyperbilirubinemia, metabolic acidosis, polycythaemia, meconium aspiration syndrome, transient tachypnoea of the newborn or respiratory distress syndrome, hyperthermia, cyanotic episodes, or loss of $>10 \%$ of birth weight.

\section{Departmental policy for macrosomic and non-macrosomic infants}

During the study period, it was the departmental policy to routinely measure blood glucose in all macrosomic infants $(\geq 4000 \mathrm{~g})$ at $1 \mathrm{~h}$ of age, followed by early feeding. Repeated measurements were performed at ages $3,6,8$ and $24 \mathrm{~h}$. In the control group, glucose was determined in every infant requiring blood test. The majority of these infants were asymptomatic screened for infection due to maternal fever, premature rupture of membranes and so on. However, some of these infants were screened to exclude symptomatic hypoglycaemia.

The department policy is to screen for sepsis at 3-6 h of age, which is similar to the schedule of glucose screening for the macrosomic infants. Newborns found to be hypoglycaemic (glucose $<40 \mathrm{mg} \%$ ) underwent repeated glucose measurement within the hour of the previous measurement. Intravenous glucose was administered to all infants with a glucose level $<40 \mathrm{mg} \%$ at $1 \mathrm{~h}$ after feeding. All infants were followed for a minimum period of $24 \mathrm{~h}$. Infants were screened for polycythae$\mathrm{mia}$ at $3 \mathrm{~h}$ of age and for hypocalcaemia at $24 \mathrm{~h}$ of age.

Glucose screening is performed in non-macrosomic infants only when symptomatic hypoglycaemia is suspected. However, a glucose test is routinely done if blood is drawn for any indication, most commonly to exclude sepsis in infants at risk for sepsis. Repeat blood testing for hypoglycaemic non-macrosomic infants is done similarly to that performed for macrosomic infants.

\section{Statistical analysis}

Data were analysed with BMDP Statistical Software. ${ }^{21}$ Univariate analysis was performed to identify differences between two groups. Student t test, Pearson's $\chi^{2}$ test, and Fisher's exact test were applied as suitable to compare groups. Statistical significance was defined as $\mathrm{p}<0.05$.

\section{RESULTS}

Of the 79031 neonates born in our medical centre during the study period, 60574 singleton full-term infants were identified and available for analysis (figure 1). They included 2766 macrosomic newborns of non-diabetic mothers who met the inclusion criteria. This group was matched to 2766 control infants. The clinical characteristics of the study and control groups are described in table 1 . Median birth weight was $4150 \mathrm{~g}$ (range 4000-5370) in the macrosomic group, and $3400 \mathrm{~g}$ (range 3000-3995) in the control group. The macrosomic group had a significantly higher percentage of male infants than the control group $(67.9 \%$ vs $53.2 \%, \mathrm{p}<0.001)$ and more caesarean deliveries. However, in the macrosomic LGA group vs the control group, there was no difference in gender. Table 2 describes the outcome of the two groups. The rate of prolonged hospitalisation was significantly higher in the macrosomic vs the control infants (OR 2.22, 95\% CI 1.96 to 2.51). No difference in the percent of neonates with prolonged hospitalisation was found comparing neonates born by vaginal delivery without complications to all macrosomic infants $(4.5 \%$ vs $4.7 \%, \mathrm{p}=0.8)$. A significantly higher number of macrosomic vs control infants were transferred to the NICU (OR 1.78, 95\% CI 1.27 to 2.53 ). The macrosomic versus control group also had significantly more infants with one or more neonatal complications (composite 


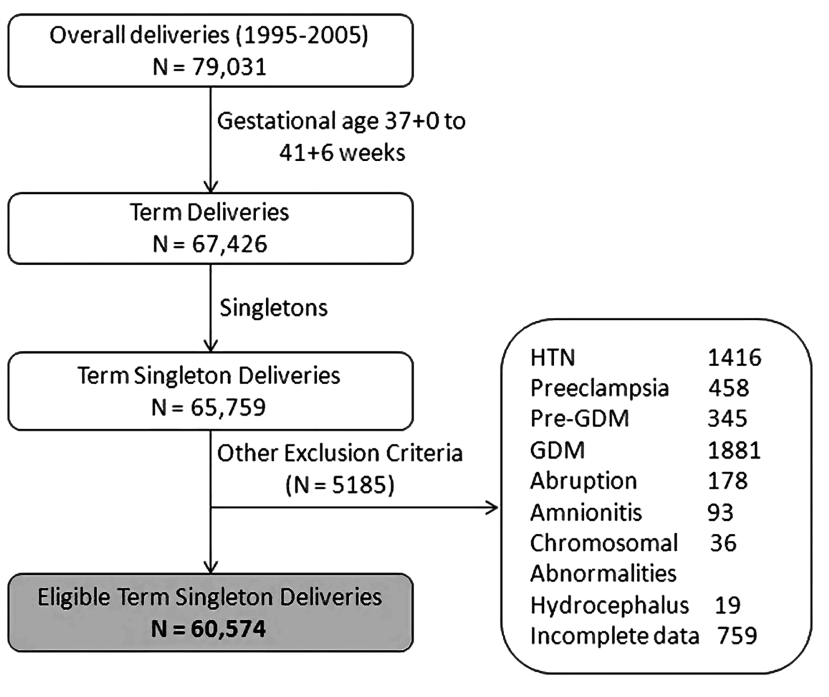

* Some of the newborns have more than one exclusion criteria

Figure 1 Study group selection.

outcome, $11.7 \%$ vs $8.0 \%, \mathrm{p}<0.001$ ) (OR 1.53, 95\% CI 1.27 to 1.83 ). The main complications were hypoglycaemia (OR 2.37, 95\% CI 1.23 to 4.81), transient tachypnoea of the newborn (OR 2.83, 95\% CI 1.53 to 5.50), hyperthermia, and birth trauma (OR 3.0, 95\% CI 1.78 to 5.62) (table 2). There were no between-group differences in rates of low 5 min Apgar score, metabolic acidosis, infection, loss of $>10 \%$ of body weight, meconium aspiration syndrome, or cyanotic episodes. No infant had symptomatic polycythaemia, and only one had hypocalcaemia.

The composite outcome was calculated for the 325 macrosomic infants with neonatal complications. They did not differ in length or head circumference from the remaining 2441 macrosomic infants, but they had significantly higher birth weights (4232 g vs $4194 \mathrm{~g}, \mathrm{p}<0.002$ ), WLRs (8.07 vs 7.99, p<0.001), BMIs (15.39 vs 15.24, p=0.004), and PI's (2.94 vs 2.91, $\mathrm{p}<0.03)$. Among the macrosomic infants with complications, there was no statistically significant difference in composite score between those who were transferred to the NICU $(n=100)$ and those who were not.

The rate of asymmetry within the macrosomic group (defined as an anthropometric index value above the 90th percentile ${ }^{22}$ ) was $63.2 \%$ by WLR, $42.4 \%$ by BMI and $22.6 \%$ by PI. Regardless of the measure used, infants defined as asymmetric were more likely to be born by caesarean delivery and less likely to be born during high-risk hours. The characteristics and outcomes of symmetric and asymmetric macrosomic infants by WLR are presented in tables 3 and 4.

The incidence of hypoglycaemia in the macrosomic infants was $1.2 \%$, and was positively associated with birth weight (table 5); $42 \%$ of the control infants were screened at least once for hypoglycaemia. Of these, only $2.2 \%$ were screened to exclude symptomatic hypoglycaemia. The prevalence of hypoglycaemia using as the denominator only neonates who underwent glucose testing showed that 14 infants $(1.2 \%)$ of the control group had hypoglycaemia compared to 33 infant $(1.2 \%)$ of the macrocosmic infants $(p>0.9)$. Similarly compared, more macrosomic LGA infants had hypoglycaemia (29 infants, $2.15 \%)$ vs tested control group infants (14 infants, $1.2 \%)(p=0.07)$. Further analysis showed that it was the asymmetric infants within the macrosomic group that accounted for most of the increased rate of hypoglycaemia (table 4). The rate of hypoglycaemia in infants with symmetric macrosomia by WLR was similar to that of the control infants (table 5).

\section{DISCUSSION}

This study evaluated the rate of neonatal complications in macrosomic newborns of non-diabetic mothers and the association of symmetry/asymmetry with the risk of neonatal complications. Macrosomic newborns are considered to be at an increased risk of hypoglycaemia, however, maternal diabetes is the underlying cause in most cases. Therefore, we limited the study group to infants of non-diabetic mothers to isolate the possible effect of birth weight. The results showed that macrosomic infants, compared to control infants, have higher rates of hypoglycaemia, transient tachypnoea of the newborn, hyperthermia, and birth trauma.

Table 1 Clinical characteristics of macrosomic and control groups

\begin{tabular}{|c|c|c|c|}
\hline Clinical characteristics & Control group $(n=2766)$ & Macrosomic group $(n=2766$ ) & Macrosomic LGA $(n=1347)$ \\
\hline Median birth weight, $g$, (range) & $3400(3000-3995)$ & $4150(4000-5370)$ & $4270(4000-5370)$ \\
\hline Mean maternal age, years (SD) & $29.61(5.0)$ & $30.66(5.08)$ & $31.09(5.02)$ \\
\hline Birth parity, median (range) & $2.0(1-12)$ & $2.0(1-17)$ & $2.0(1-16)$ \\
\hline Mean head circumference, cm (SD) & $34.61(1.05)$ & $35.9(1.02)$ & $35.98(1.03)$ \\
\hline Mean length, $\mathrm{cm}$ (SD) & $50.4(1.3)$ & $52.5(1.42)$ & $52.67(1.43)$ \\
\hline AGA according to length, $n(\%)$ & $2766(100)$ & $1786(64.6)$ & $684(50.8)$ \\
\hline AGA according to weight, $n(\%)$ & $2766(100)$ & $1419(51.3)$ & $0(0)$ \\
\hline Mean WLR, kg/m (SD) & $6.78(0.44)$ & $8.0(0.35)$ & $8.18(0.35)$ \\
\hline Mean BMI, kg/m² (SD) & $13.46(0.89)$ & $15.25(0.91)$ & $15.54(0.88)$ \\
\hline Mean $\mathrm{Pl}, \mathrm{g} / \mathrm{cm}^{3 *} 100$ (SD) & $2.67(0.2)$ & $2.91(0.24)$ & $2.96(0.23)$ \\
\hline Male, n (\%) & $1472(53.2)$ & $1877(67.9)$ & $736(54.6)^{*}$ \\
\hline Vaginal delivery, n (\%) & $2160(78.1)$ & $1728(62.5)$ & $737(54.7)$ \\
\hline Caesarean delivery, n (\%) & $406(14.7)$ & $899(32.5)$ & $561(41.6)$ \\
\hline Instrumental delivery, n (\%) & $200(7.2)$ & $139(5)$ & $49(3.6)$ \\
\hline Birth in high-risk time period, $\mathrm{n}(\%)$ & $2090(75.7)$ & $1822(71.6)$ & $851(68.5)$ \\
\hline
\end{tabular}


Table 2 Outcome of macrosomic and control groups

\begin{tabular}{|c|c|c|c|c|c|}
\hline Outcome parameters & Macrosomic group $(n=2766)$ & Control group $(n=2766)$ & p Values* & Macrosomic LGA $(n=1347)$ & p Valuest \\
\hline NICU transfer, $\mathrm{n}(\%)$ & $100(3.6)$ & $57(2.1)$ & $<0.001$ & $53(3.9)$ & $<0.001$ \\
\hline Prolonged hospitalisation, $\mathrm{n}(\%)$ & $959(34.7)$ & $534(19.3)$ & $<0.001$ & $579(43)$ & $<0.001$ \\
\hline Composite outcome, $\mathrm{n}(\%) \ddagger$ & $325(11.7)$ & $222(8.0)$ & $<0.001$ & $185(13.7)$ & $<0.001$ \\
\hline Infants with any birth trauma, $\mathrm{n}(\%)$ & $55(2)$ & $18(0.7)$ & $<0.001$ & $28(2.1)$ & $<0.001$ \\
\hline Fracture of clavicle, $\mathrm{n}(\%)$ & $51(1.8)$ & $15(0.5)$ & $<0.001$ & $26(1.9)$ & $<0.001$ \\
\hline Respiratory disorders, $\mathrm{n}(\%)$ & $42(1.5)$ & $15(0.5)$ & $<0.001$ & $20(1.5)$ & 0.003 \\
\hline Hypoglycaemia, n (\%) & $33(1.2)$ & $14(0.5)$ & 0.008 & $29(2.2)$ & $<0.001$ \\
\hline Hyperthermia, n (\%) & $16(0.6)$ & $4(0.1)$ & 0.012 & $6(0.4)$ & 0.09 \\
\hline Unexplained jaundice, n (\%) & $149(5.4)$ & $132(4.8)$ & 0.33 & $90(6.7)$ & 0.012 \\
\hline Hypoxic ischaemic encephalopathy, n (\%) & $16(0.6)$ & $8(0.3)$ & 0.15 & $8(0.6)$ & 0.18 \\
\hline Polycytemia, n (\%) & $11(0.4)$ & $6(0.2)$ & 0.33 & $7(0.5)$ & 0.14 \\
\hline Cyanotic event, n (\%) & $9(0.3)$ & $8(0.3)$ & 0.81 & $6(0.4)$ & 0.41 \\
\hline Culture-positive sepsis, n (\%) & $8(0.3)$ & $6(0.2)$ & 0.79 & $5(0.4)$ & 0.35 \\
\hline Leukocytosis, n (\%) & $7(0.3)$ & $1(0)$ & 0.07 & $3(0.2)$ & 0.1 \\
\hline Weight loss $>10 \%, n(\%)$ & $6(0.2)$ & $9(0.3)$ & 0.61 & $5(0.4)$ & 0.78 \\
\hline Thrombocytopenia, n (\%) & $5(0.2)$ & $4(0.1)$ & 0.75 & $4(0.3)$ & 0.45 \\
\hline Hypocalcaemia, n (\%) & $1(0)$ & 0 & 0.98 & $1(0.1)$ & 0.33 \\
\hline Meconium aspiration, $\mathrm{n}(\%)$ & $1(0)$ & 0 & 0.98 & 0 & 0.98 \\
\hline
\end{tabular}

${ }^{*} \mathrm{p}$ Values between macrosomic and control groups

tp Values between macrosomic LGA and control groups.

$\neq$ Defined as one or more of the following: 5 min Apgar score $<7$, asphyxia, convulsions, birth injury, hypoglycaemia, hypocalcaemia, unexplained hyperbilirubinemia, metabolic acidosis, polycythaemia, meconium aspiration syndrome, transient tachypnoea of the newborn or respiratory distress syndrome, hyperthermia, cyanotic episodes or loss of $>10 \%$ of birth weight.

LGA, large for gestational age; NICU, neonatal intensive care unit.

The few studies that have assessed the rate of hypoglycaemia in macrosomic newborns of non-diabetic mothers reported rates of $3.8-16 \% .^{23-26}$ The wide range was mainly due to differences in the definition of hypoglycaemia, which is still controversial. We selected a definition that provided us a safety margin for prevention and treatment. We sought to maintain plasma glucose concentrations in asymptomatic infants at $>40 \mathrm{mg} / \mathrm{dL}^{27}$ Accordingly, the rate of hypoglycaemia in our study group was $1.2 \%$, which is far lower than previously reported in macrosomic infants. ${ }^{23-26}$ The rate of hypoglycaemia was positively associated with birth weight, ranging from $0.8 \%$ in infants with a birth weight of $4000-4499 \mathrm{~g}$ to $25 \%$ in infants with a birth weight of $\geq 5000 \mathrm{~g}$.

The macrosomic group was defined by three anthropometric measures. The type of measure used influenced the results, with rates of asymmetry varying from $63.2 \%$ when macrosomia was defined by WLR, to $42.4 \%$ when BMI was used, to $22.6 \%$ when PI was used. Several similar studies to ours have been conducted, but the different anthropometric parameters applied led to inconsistent results. ${ }^{25}$ 28-33 For example, using PI, Ballard et $a l^{28}$ reported an asymmetry rate of $12.5 \%$, which is considerably lower than our $22.6 \%$. Persson et $\mathrm{al}^{29}{ }^{30}$ reported a rate of $35 \%$, however, infants of diabetic mothers were included in this study.

We found that the tool with the most highly significant results for identifying macrosomic infants at risk for hypoglycaemia was WLR, ${ }^{24}$ however, BMI was also significant, but less so, while PI was not found to be significant, by contrast with others. ${ }^{31-33}$ The use of WLR, is a simpler concept than BMI or PI, and it is less prone to error because the length measurement is not squared or cubed. Characterisation of the macrosomic infants by low risk (symmetric macrosomia) or high risk

Table 3 Comparison of clinical characteristics of symmetric and asymmetric macrosomic infants by WLR

\begin{tabular}{|c|c|c|c|}
\hline Clinical characteristics & Symmetric by WLR $(n=1020)$ & Asymmetric by WLR $(n=1746)$ & p Value \\
\hline Mean maternal age, years (SD) & $30.38(5.0)$ & $30.82(5.12)$ & 0.027 \\
\hline Birth weight, $g$, median (range) & $4080(4000-4500)$ & $4210(4000-5370)$ & $<0.001$ \\
\hline Mean head circumference, cm (SD) & $35.88(1.01)$ & $35.92(1.02)$ & 0.29 \\
\hline Mean length, $\mathrm{cm}(\mathrm{SD})$ & $53.1(1.16)$ & $52.16(1.45)$ & $<0.001$ \\
\hline AGA according to length, $n(\%)$ & $614(60.2)$ & $1172(67.1)$ & $<0.001$ \\
\hline AGA according to weight, $n(\%)$ & $923(90.5)$ & $496(28.4)$ & $<0.001$ \\
\hline Mean WLR, kg/m (SD) & $7.73(0.17)$ & $8.16(0.32)$ & $<0.001$ \\
\hline Male, n (\%) & $855(83.8)$ & $1022(58.5)$ & $<0.001$ \\
\hline Vaginal delivery, $\mathrm{n}(\%)$ & $736(72.2)$ & $992(56.8)$ & $<0.001$ \\
\hline Caesarean delivery, $\mathrm{n}(\%)$ & $213(20.9)$ & $686(39.3)$ & $<0.001$ \\
\hline Instrumental delivery, $\mathrm{n}(\%)$ & $71(7)$ & $68(3.9)$ & $<0.001$ \\
\hline Birth during high-risk time period, $\mathrm{n}(\%)$ & $711(75.4)$ & $1111(69.4)$ & 0.001 \\
\hline
\end{tabular}


Table 4 Comparison of outcomes of symmetric and asymmetric macrosomic infants by WLR

\begin{tabular}{|c|c|c|c|}
\hline Outcome parameters & Symmetric by WLR $(n=1020)$ & Asymmetric by WLR ( $n=1746)$ & $\mathrm{p}$ Values \\
\hline Composite outcome, $n(\%)^{*}$ & $94(9.2)$ & $231(13.2)$ & 0.001 \\
\hline Unexplained jaundice, n (\%) & $40(3.9)$ & $109(6.2)$ & 0.009 \\
\hline Hypoglycaemia, n (\%) & $3(0.3)$ & $30(1.7)$ & $<0.001$ \\
\hline NICU transfer, $\mathrm{n}(\%)$ & $29(2.8)$ & $71(4.1)$ & 0.11 \\
\hline Prolonged hospitalisation, n (\%) & $247(24.2)$ & $712(40.8)$ & $<0.001$ \\
\hline Respiratory disorders, $\mathrm{n}(\%)$ & $14(1.4)$ & $28(1.6)$ & 0.75 \\
\hline Any birth trauma, $\mathrm{n}(\%)$ & $15(1.5)$ & $40(2.3)$ & 0.16 \\
\hline Fracture of clavicle, $n(\%)$ & $15(1.5)$ & $36(2.1)$ & 0.31 \\
\hline Hyperthermia, n (\%) & $6(0.6)$ & $10(0.6)$ & 0.99 \\
\hline Hypoxic ischaemic encephalopathy, $n$ (\%) & $5(0.5)$ & $11(0.6)$ & 0.8 \\
\hline Culture-positive sepsis, n (\%) & $3(0.3)$ & $5(0.3)$ & 0.97 \\
\hline Leukocytosis, n (\%) & $3(0.3)$ & $4(0.2)$ & 0.71 \\
\hline Polycythaemia, n (\%) & $2(0.2)$ & $9(0.5)$ & 0.35 \\
\hline Thrombocytopenia, n (\%) & $2(0.2)$ & $3(0.25)$ & 0.98 \\
\hline Cyanotic event, n (\%) & $2(0.2)$ & $7(0.4)$ & 0.5 \\
\hline Hypocalcaemia, n (\%) & $1(0.1)$ & 0 & 0.37 \\
\hline Weight loss >10\%, n (\%) & 0 & $6(0.3)$ & 0.09 \\
\hline Meconium aspiration, $n$ (\%) & 0 & $1(0.1)$ & 0.79 \\
\hline
\end{tabular}

(asymmetric macrosomia) revealed a significantly higher rate of hypoglycaemia in the asymmetric macrosomic subgroup. Indeed, symmetric macrosomic newborns of non-diabetic mothers, as defined by WLR, had a similar hypoglycaemic rate compared to control infants (table 5). These findings suggest that repeated glucose testing of symmetric macrosomic newborns (defined by WLR) of non-diabetic mothers is not justified. Our results differ from those of Schaefer-Graf et $a l^{34}$ who failed to find a correlation between anthropometric parameters and hypoglycaemia, possibly due to an inaccuracy in neonatal length measurement. Previous studies advocated the use of symmetric versus asymmetric growth to assess the risk of hypoglycaemia or other neonatal complications. Ballard et $a l^{28}$ and Djelmis et $a l^{35}$ studied newborns of diabetic mothers and suggested that hyperglycaemia in utero causes a disproportion in growth, and when this occurs, more neonatal complications are observed, such as hypoglycaemia, hyperbilirubinemia, polycythaemia and metabolic acidosis. $^{28} 35$ This hypothesis was supported by Van Assche et $a l^{36}$ who claimed that symmetric growth is explained

Table 5 Incidence of hypoglycaemia in macrosomic and control infants

\begin{tabular}{ll}
\hline Hypolycaemia $(\mathrm{n} / \mathrm{N})$ & Infant group \\
\hline $33 / 2766(1.2)$ & All macrosomic infants* $\mathrm{n}(\%)$ \\
$20 / 2564(0.8)$ & Birth weight $4000-4499 \mathrm{~g} \mathrm{n}(\%)$ \\
$11 / 194(5.7)$ & Birth weight $4500-4999 \mathrm{~g} \mathrm{n}(\%)$ \\
$2 / 8(25)$ & Birth weight $\geq 5000 \mathrm{~g} \mathrm{n}(\%)$ \\
$17 / 2140(0.8)$ & Symmetric macrosomic infants by PI, $\mathrm{n} \mathrm{( \% )}$ \\
$10 / 1593(0.6)$ & Symmetric macrosomic infants by BMI, $\mathrm{n}(\%)$ \\
$3 / 1018(0.3)$ & Symmetric macrosomic infants by WLR, $\mathrm{n}(\%)$ \\
$14 / 2766(0.5)$ & Control infants, $\mathrm{n}(\%)$ \\
\hline
\end{tabular}

${ }^{*}$ Birth weight $>4000 \mathrm{~g}$.

$\mathrm{PI}$, Ponderal Index; BMI, Body Mass Index; WLR, weight/length ratio. by genetic constitutional factors, whereas, asymmetric growth is explained by an abnormal metabolic environment.

A significantly higher percent of the macrosomic group had prolonged hospital stay. This may be partially attributable to the high rate of caesarean deliveries in the macrosomic group, leading to longer maternal hospital stay. ${ }^{37}$ Furthermore, caesarean delivery is known to be associated with an increased incidence of transient tachypnoea of the newborn, ${ }^{38}$ which was also true for our macrosomic group. The reason for the slightly increased rate of hyperthermia in the macrosomic group is unclear, as no cases of infection were identified. It is possible that macrosomic infants require less heating, so that the standard placement of infants under a radiant warmer after delivery may be excessive in these cases. Hyperthermia in these neonates could also result from dehydration.

The higher incidence of birth trauma (mainly fracture of the clavicle) was not correlated to any of the anthropometric parameters except head circumference. It is likely that the low incidence of brachial plexus injury relative to reports in the medical literature was also related to the high rate of caesarean deliveries. $^{4} 25$

In conclusion, macrosomic infants of non-diabetic mothers are at an increased risk of neonatal complications. As symptomatic hypocalcaemia and polycythaemia were not identified in this population, we believe routine measurements of haematocrit and calcium may not be required. Symmetric macrosomic infants (defined by WLR) have a similar rate of hypoglycaemia as normal weight infants. Thus, these infants do not seem to require repeat glucose testing.

Acknowledgements The authors wish to thank Mrs Pearl Lilos for excellent statistical analysis.

Contributors Details of the contribution of individual authors: NL: guarantor, conception and design of study, data interpretation, revision of the article. YL: data analysis, article drafting. AK, NM and YY: intellectual input and design of the study, revision of the article. EF: data analysis and interpretation, intellectual input, revision of the article. FK: data analysis and interpretation, revision of the article. GK: design, analysis, revision of article. All co-authors have approved the final version of the 
article, confirm that the work has not been published/submitted elsewhere and agree with submission. All co-authors agree to be accountable for all aspects of the work in ensuring that questions related to the accuracy or integrity of any part of the work are appropriately investigated and resolved.

Competing interests None.

Ethics approval Rabin Medical Center research review board.

Provenance and peer review Not commissioned; externally peer reviewed.

\section{REFERENCES}

1 Henriksen T. The macrosomic fetus: a challenge in current obstetrics. Acta Obstet Gynecol Scand 2008:87:134-45.

2 American College of Obstetricians and Gynecologists. Fetal macrosomia. Washington, DC: ACOG Technical Bulletin 1991: No.159.

3 Gross TL, Sokol RJ, Williams T, et al. Shoulder dystocia: a fetal-physician risk. Am J Obstet Gynecol 1987;156:1408-18.

4 Gonen R, Bader D, Ajami M. Effects of a policy of elective cesarean delivery in cases of suspected fetal macrosomia on the incidence of brachial plexus injury and the rate of cesarean delivery. Am J Obstet Gynecol 2000;183:1296-300.

5 Bromwich P. Big babies. Br Med J 1986;293:1387-8

6 Lipscombe KR, Gregory K, Shaw K. The outcome of macrosomic infants weighing at least 4500 grams. Los Angeles County+University of Southern California experience. Obstet Gynecol 1995;85:558-64.

7 Lavin JP Jr, Lovelace DR, Miodovnik M, et al. Clinical experience with one hundred seven diabetic pregnancies. Am J Obstet Gynecol 1983;147:742-52.

8 Thomson AM, Billewicz WZ, Hytten FE. The assessment of fetal growth. J Obstet Gynaecol Br Commonw 1968;75:903-16.

9 Rohrer F. Eineneue Formelzur Bestimmung der Korperfulle, Korrespondenze. Blatt der DeutschenGesellschaft fur Anthrophologie, Ethnologie und Urgeschichte 1908:39:5-7. [Article in German)]

10 Cole TJ, Freeman JV, Preece MA. Body mass index reference curves for the UK, 1990. Arch Dis Child 1995:73:25-9.

11 Dombrowski MP, Berry SM, Johnson MP, et al. Birth weight-length ratios, ponderal indexes, placental weights, and birth weight-placenta ratios in a large population. Arch Pediatr Adolesc Med 1994;148:508-12.

12 Florey Cdu V. The use and interpretation of ponderal index and other weight-height ratios in epidemiological studies. J Chronic Dis 1970;23:93-103.

13 Khosla T, Lowe CR. Indices of obesity derived from body weight and height. $\mathrm{Br} J$ Prev Soc Med 1967;21:122-8.

14 Rolland-Cachera MF, Sempé M, Guilloud-Bataille M, et al. Adiposity indices in children. Am J Clin Nutr 1982:36:178-84.

15 Patterson RM, Pouliot MR. Neonatal morphometrics and perinatal outcome: who is growth retarded? Am J Obstet Gynecol 1987:157:691-3.

16 Greer FR. Intrauterine growth as estimated from live born birth-weight data at 24 to 42 weeks of gestation, by Lula 0. Lubchenco, et al. Pediatrics 1963;32:793-800. Pediatrics 1998;102:237-9.

17 Davidson S, Sokolover N, Erlich A, et al. New and improved Israeli reference of birth weight, birth length and head circumference by gestational age: a hospital based study. Isr Med Assoc J 2008;10:130-4.
18 Ogata ES. Carbohydrate homeostasis. In: MacDonald MG, Seshia MMK, Mullett MD, eds. Avery's Neonatology. 6th edn. Philadelphia: Lippincott Williams \& Wilkins, 2005:876-91.

19 Maisels MJ. Jaundice in healthy newborns-redefining physiologic jaundice. West J Med 1988;149:451.

20 Black VD, Lubchenco LO, Luckey DW, et al. Developmental and neurologic sequelae of neonatal hyperviscosity syndrome. Pediatrics 1982;69:426-31.

21 Dixon WJ. BMDP statistical software. Los Angeles, CA: University of California, 1993.

22 Davidson S, Natan D, Novikov I, et al. Body mass index and weight-for-length ratio references for infants born at 33-42 weeks gestation: a new tool for anthropometric assessment. Clin Nutr 2011;30:634-9.

23 Tallarigo L, Giampetro O, Penno G, et al. Relation of glucose tolerance to complications of pregnancy in nondiabetic women. $N$ Engl I Med 1986:315:989-92.

24 Araz N, Araz M. Frequency of neonatal hypoglycemia in large for gestational age infants of non-diabetic mothers in a community maternity hospital. Acta Medica 2006;49:237-9.

25 Bertagnon JRD, Segre CAM, DallColletto GM. Weight-for-length relationship at birth to predict neonatal diseases. São Paulo Med J 2003;121:149-54.

26 Gyurkovits Z, Kálló K, Bakki J, et al. Neonatal outcome of macrosomic infants: an analysis of a two-year period. Eur J Obstet Gynecol Reprod Biol 2011;159:289-92.

27 Adamkin DH and Committee on Fetus and Newborn. Postnatal glucose homeostasis in late-preterm and term infants. Pediatrics 2011;127:575-9.

28 Ballard JL, Rosenn B, Khoury JC, et al. Diabetic fetal macrosomia: significance of disproportionate growth. J Pediatr 1993;122:115-9.

29 Persson M, Pasupathy D, Hanson U, et al. Birth size distribution in 3,705 infants born to mothers with type 1 diabetes. Diabetes Care 2011;34:1145-49.

30 Persson $\mathrm{M}$, Pasupathy $\mathrm{D}$, Hanson U, et al. Disproportionate body composition and perinatal outcome in large-for-gestational-age infants to mothers with type diabetes. BJOG 2012;119:565-72.

31 Bollepalli S, Dolan LM, Miodovnik M, et al. Asymmetric large-for-gestational-age infants of type 1 diabetic women: morbidity and abdominal growth. Am J Perinatol 2010;27:603-10.

32 Rasmussen S, Kiserud T, Albrechtsen S. Foetal size and body proportion at 17-19 weeks of gestation and neonatal size, proportion, and outcome. Early Hum Dev 2006;82:683-90.

33 Landmann E, Reiss I, Misselwitz B, et al. Ponderal index for discrimination between symmetric and asymmetric growth restriction: percentiles for neonates from 30 weeks to 43 weeks of gestation. J Matern Fetal Neonatal Med 2006;19:157-60.

34 Schaefer-Graf UM, Rossi R, Bührer C, et al. Rate and risk factors of hypoglycemia in large-for-gestational-age newborn infants of nondiabetic mothers. Am J Obstet Gynecol 2002;187:913-7.

35 Djelmis J, Bukovic D, Pfeifer D, et al. Ponderal index and disproportionate fetal growth in IDDM pregnancies. Coll Antropol 1998:22:491-5.

36 Van Assche FA. Symmetric and asymmetric fetal macrosomia in relation to long term consequences. Am J Obstet Gynecol 1997;177:1563-4.

37 Ju H, Chadha Y, Donovan T, et al. Fetal macrosomia and pregnancy outcomes. Aust N Z J Obstet Gynaecol 2009:49:504-9.

38 Rawlings JS, Smith FR. Transient tachypnea of the newborn. An analysis of neonatal and obstetric risk factors. Am J Dis Child 1984;138:869-71. 